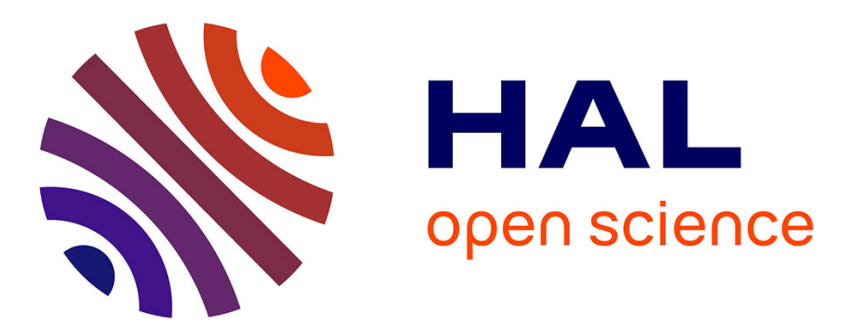

\title{
Phase transformation behavior of thin shape memory alloy wires embedded in a polymer matrix composite
}

\author{
J.-E. Bidaux, L. Bataillard, J.-A. Månson, R. Gotthardt
}

\section{To cite this version:}

J.-E. Bidaux, L. Bataillard, J.-A. Månson, R. Gotthardt. Phase transformation behavior of thin shape memory alloy wires embedded in a polymer matrix composite. Journal de Physique IV Proceedings, 1993, 03 (C7), pp.C7-561-C7-564. 10.1051/jp4:1993793 . jpa-00252213

\section{HAL Id: jpa-00252213 https://hal.science/jpa-00252213}

Submitted on 1 Jan 1993

HAL is a multi-disciplinary open access archive for the deposit and dissemination of scientific research documents, whether they are published or not. The documents may come from teaching and research institutions in France or abroad, or from public or private research centers.
L'archive ouverte pluridisciplinaire HAL, est destinée au dépôt et à la diffusion de documents scientifiques de niveau recherche, publiés ou non, émanant des établissements d'enseignement et de recherche français ou étrangers, des laboratoires publics ou privés. 


\title{
Phase transformation behavior of thin shape memory alloy wires embedded in a polymer matrix composite
}

\author{
J.-E. BIDAUX, L. BATAILLARD*, J.-A. MÅNSON and R. GOTTHARDT* \\ Laboratoire de Technologie des Composites et Polymères, Ecole Polytechnique Fédérale de Lausanne, \\ 1015 Lausanne, Switzerland \\ * Institut de Génie Atomique, Ecole Polytechnique Fédérale de Lausanne, 1015 Lausanne, Switzerland
}

\begin{abstract}
Shape memory alloy composites (SMA-composites) are adaptive materials, whose external shape or mechanical properties can be controlled by the activation of embedded SMA actuators. While considerable information is now available on the structural, mechanical and functional behavior of plain SMAs, nearly nothing is known about embedded SMAs. However, the characteristics of the matrix, and its viscoelastic properties in particular, can have an influence on the martensitic transformation and therefore on the functional properties of the SMA actuator. Accordingly, there is a considerable interest in studying the transformation behavior of embedded SMA. In this work, the transformation behavior of thin $\mathrm{NiTi}$ wires, incorporated into epoxy resin is studied by dynamic mechanical analysis and calorimetry. The dynamic mechanical behavior of the SMA composites is compared to that of plain SMA wires. Simple beam bending theory is used to predict the dynamic moduli of the SMA composite from the measured dynamic moduli of the constituents as input data. The difference between the predicted and the measured behavior is analyzed in term of SMA/matrix interaction.
\end{abstract}

\section{Introduction}

Shape memory alloys (SMA) can be used as thermally activated actuators and have found applications for instance in thermostats, fire alarms, or connectors. A relatively new type of application of SMAs is as embedded sensors and actuators in composites [1]. Thin SMA wires are particularly suitable in this respect because of their flexibility and fast response. An example of the use of embedded SMA wires is the development of SMA-silicone rubber composite fingers for robotic applications: the SMA wire is used to modify the shape and the silicone rubber acts as a spring to create or enhance the two way shape memory effect [2]. Experiences of active stiffness control of a composite beam have also been realized and bending stiffness increase of up to $100 \%$ were obtained using embedded SMA wires activated by electrical current heating $[1,3,4]$.

While considerable information is now available on the structural, mechanical and functional behavior of the plain SMA, virtually nothing is known about the behavior of embedded SMA. However, the transformation behavior of the SMA embedded in a matrix might be different from a plain SMA. In the matrix, the phase transformation is constrained, the transformation strain being limited by the elasticity or plasticity of the matrix. Furthermore, strong internal stresses that exist at the SMA/polymer interface due to thermal coefficient mismatch between SMA and matrix can have an influence on the martensite variant morphology and therefore on the mechanical and functional properties.

In this work, the transformation behavior of SMA/epoxy composites is studied by dynamic mechanical analysis and is compared to that of neat SMA wires. Simple beam bending theory is used to predict the bending stiffness and tan $\delta$ of the SMA composite starting from the measured dynamic moduli of the constituents (epoxy, SMA) as input data. The difference between the calculated and the measured behavior is analyzed in term of SMA/matrix interaction. 


\section{Experimental}

The specimen was prepared using a silicon mold. During molding a small $10 \mathrm{~N}$ force was applied on each individual wire to ensure a good alignment of the wires. The SMA wires were NiTi thin wires $(50 \% \mathrm{Ni}$, $50 \% \mathrm{Ti}$ ) with a diameter of $300 \mu \mathrm{m}$ produced by Microfil Industries in Renens, Switzerland. The wires were annealed $30 \mathrm{~min}$ at $550^{\circ} \mathrm{C}$ in an argon atmosphere and then embedded as shown in Fig. 1. The matrix was an epoxy resin (LYY 556, Ciba-Geigy) cured $4 \mathrm{~h}$ at $80^{\circ} \mathrm{C}$ and $4 \mathrm{~h}$ at $120^{\circ} \mathrm{C}\left(\mathrm{Tg}=120^{\circ} \mathrm{C}\right)$ according to the supplier's indications.

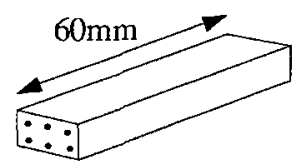

a)

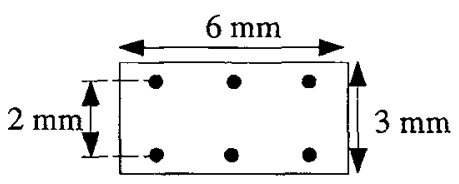

b)

Fig 1. Sample geometry: SMA wires with a diameter of 300 um are embedded in epoxy resin, each $1 \mathrm{~mm}$ apart from the neutral axis a) full sample b) cross section

Dynamic mechanical properties were measured using a RSA2 rheometer from Rheometrics. Because of limitations due to transducer compliance, measurements were done in the so-called tension-compression mode for the plain wire and in three point bending mode for the composite. However, the maximum strain amplitude was kept at the same value. A static stress $10 \%$ higher than the dynamic stress was superposed to the dynamic stress. This was necessary to keep the total applied force positive (to avoid buckling of the wire). As will be shown in the following, this static stress allowed the simultaneous observation of the shape memory effect. The measurements were done at the heating/cooling rate of $3 \mathrm{~K} / \mathrm{min}$ and at the frequency of $1 \mathrm{~Hz}$. Calorimetric measurements were done using a DSC7 from PerkinElmer at the heating/cooling rate of $10 \mathrm{~K} / \mathrm{min}$.

\section{Results}

The SMA wire: Fig. 2 shows a typical result for a plain SMA wire. Characteristic hysteris loops (heating, cooling) related to the onset of the martensitic transformation in the SMA material can be observed. The $E^{\prime}$ modulus drops by more than $30 \%$ when cooling from the high temperature austenitic phase to the low temperature martensitic phase. The comparison with the static strain curve and DSC data (Fig. 3) allows the identification of the exact position of the precursor $R$ phase transformation temperature (see R, Fig. 2) and the real martensitic transformation temperature (Ms). The $\mathrm{E}^{\prime}$ modulus passes through a minimum value which can be due either to an elastic constant softening [5] or to the motion of the interfaces between the different $R$ phase variants [5] or a combination of the two. The static strain curve exhibits the so-called shapememory-effect, the deformation experienced on cooling (about $0.3 \%$ ) being fully recovered on heating against the applied load.

The epoxy matrix: In Fig. 4 are reported the same parameters as in Fig. 2 but for the epoxy matrix. Since the glass transition

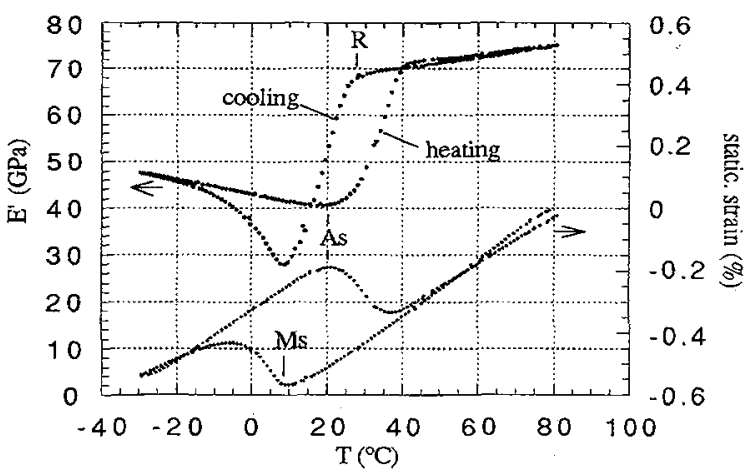

Fig. 2 Plain NiTi wire: elastic modulus and static strain versus temperature, dynamic strain: $5^{*} 10^{-4}$, heating/cooling rate: $3 \mathrm{~K} / \mathrm{min}$, frequency: $1 \mathrm{~Hz}$ temperature is about $120^{\circ} \mathrm{C}$ and the $\beta$ transition temperature $-50^{\circ} \mathrm{C}$, the elastic modulus is almost linear in the temperature range considered here. The small hysteresis loop observed is due to the fact that the measurements were performed at the heating/cooling rate of $3 \mathrm{~K} / \mathrm{min}$. 
The SMA-composite: Fig. 5 shows a typical behavior of an SMA-composite containing SMA wires identical to the one previously measured in Fig. 2. A total decrease of the effective bending stiffness ( $E_{\text {eff }}^{\prime}$ ) of about $20 \%$ is observed when the sample undergoes its martensitic transformation. Unlike for the plain SMA, this decrease occurs in two welldefined steps. Comparison with the DSC scan (Fig. 3) suggests that the first step is associated with the $\mathrm{R}$ phase transition and the other one with the real martensitic transformation. These two transformations stages were not observed in a previous study [4] because in that case the SMA wire had been annealed at $800^{\circ} \mathrm{C}$ prior to embedding which led to the suppression of the $R$ phase transition. A reversible static strain change (shape memory effect) of about $0.1 \%$ is observed at the transition. In Fig. 6, the measured $E_{\text {eff }}^{\prime}$ is compared to the result of a simple beam bending theory prediction where dynamic moduli of matrix and SMA wire were used as input data. The effective bending stiffness and $\tan \delta$ were calculated following [4] and using the elastic-viscoelastic correspondence principle [6]. It is seen that, for the heating curve, the measured $E^{\prime}$ eff varies as predicted, showing a relative modulus increase of $\sim 20 \%$. This agreement indicates that the phase transformation in the composite has gone to completion, as in the plain SMA wires. The bending stiffness variation is quite promising for further applications, since the SMA volume fraction is relatively low $(2.4 \%)$.

The prediction underestimates the absolute value of $E_{\text {eff. This can probably be explained }}$ on the one hand by the fact that a kind of rule of mixture is used for the calculation which does not take into account the difference in Poisson's coefficient between matrix and wire. On the other hand, our sample shape is intermediate between a plate and a beam. Since the bending stiffness of a plate is higher than the one of a beam by about $16 \%$ this could be another reason for the discrepancy. These corrections would lead to a higher predicted modulus and a better agreement with the data.

The difference observed between the two cooling curves is more significant for us. $\mathrm{E}_{\text {eff }}^{\prime}$ drops in two steps without the very low minimum value observed for plain SMA. We have verified that it is not due to the fact that measurements were done in 3 point-bending for the SMA-comp. and in tensioncompression for the plain wire: additional measurements, not reported here, of single wires embedded in epoxy measured in tension-compression gave the same result.

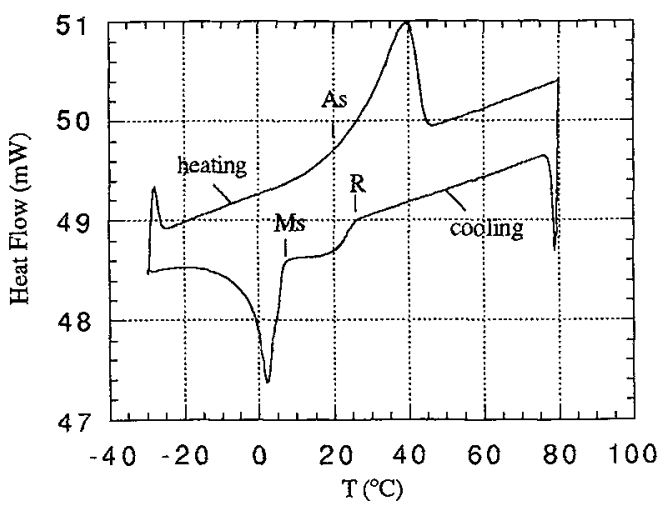

Fig. 3 Plain NiTi wire: DSC scan at $10 \mathrm{~K} / \mathrm{min}$

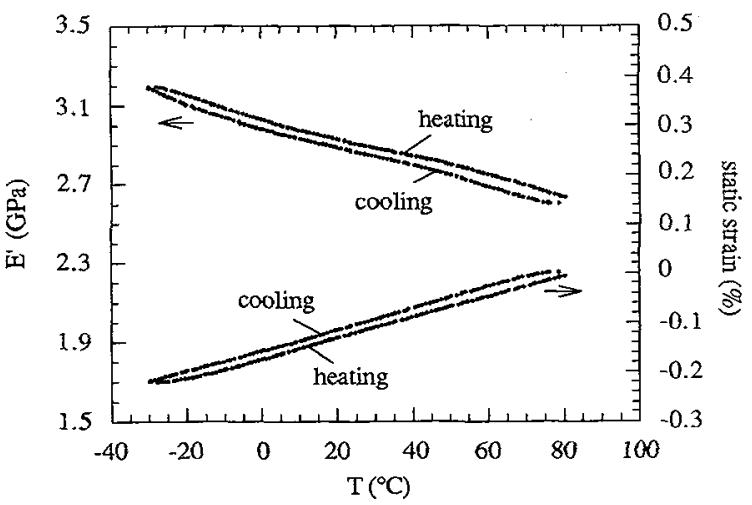

Fig. 4 Epoxy matrix: elastic modulus and static strain versus temperature measured in 3 point bending, dynamic strain: $5^{*} 10-4$, static load $\approx 200 \mathrm{~g}$, heating/cooling rate: $3 \mathrm{~K} / \mathrm{min}$

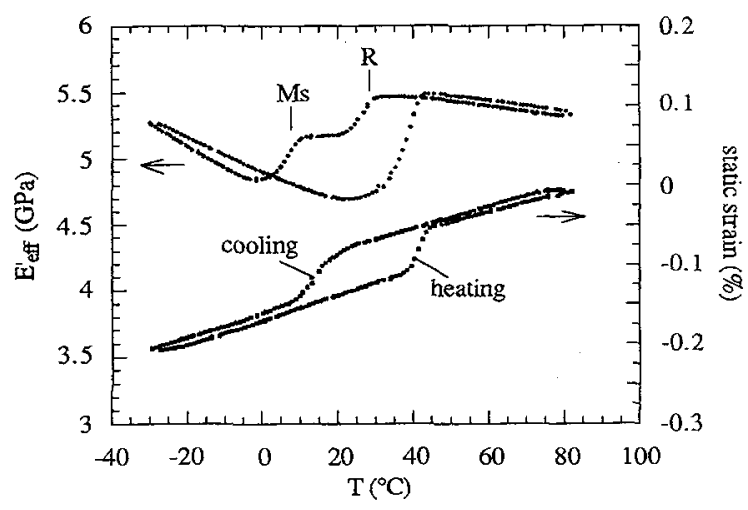

Fig. 5 SMA-composite (NiTi/epoxy): effective bending stiffness and static strain versus temperature measured in 3 point bending, dynamic strain: $5^{*} 10-4$, static load $\approx 200 \mathrm{~g}$, heating/cooling rate: $3 \mathrm{~K} / \mathrm{min}$, frequency: $1 \mathrm{~Hz}$ 


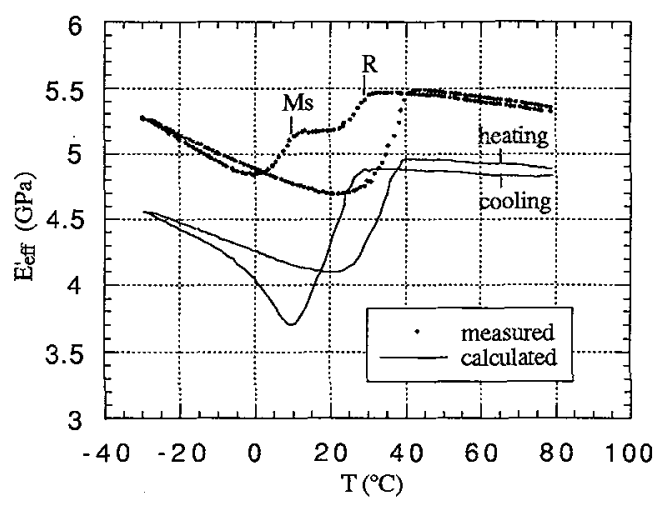

a)

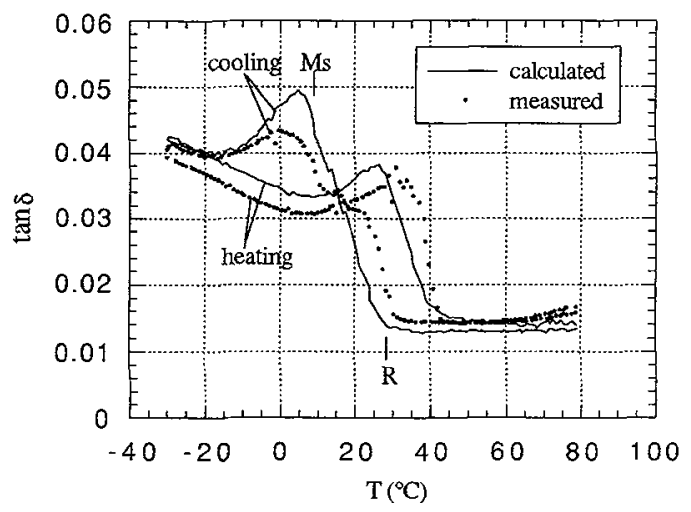

b)

Fig. 6 SMA-composite (NiTi/epoxy): measured effective dynamic modulus (a) and $\tan \delta$ (b) versus temperature measured in 3 point bending compared to calculated values using beam bending theory and measured SMA wire and matrix dynamic properties as input data, static load $=200 \mathrm{~g}$, dynamic strain: $5^{*} 10^{-4}$, heating/cooling rate: $3 \mathrm{~K} / \mathrm{min}$, frequency: $1 \mathrm{~Hz}$

As suggested above, the first step seems to be associated with the $\mathrm{R}$ phase transformation and the second one with the martensitic transformation. Apparently, in the composite, the elastic softening associated with the $\mathrm{R}$ phase transformation is inhibited. We think that this might be an effect of the interaction between the SMA material and the matrix in the composite. Two explanations can be proposed: i) the $\mathrm{R}$ phase transformation in itself is modified because the SMA is constrained by the matrix. ii) the $R$ transformation is not modified, but the fine domain structure of the product phase is changed (selection of the variants because of the internal stresses). The $\tan \delta$ curve (Fig. $5 \mathrm{~b}$ ) as well as the bending stiffness curve shows the influence of SMA/matrix interaction: two peaks are observed on cooling. This leads to the important conclusion that the behavior of the SMA-composite is not merely the superposition of the matrix and the SMA behavior respectively but results in new properties. However, this point needs clarification and will be investigated further in the near future.

\section{Conclusion}

The transformation behavior of embedded thin SMA wires has been found to be different from the one of plain SMA wires. The bending stiffness of the SMA-composite decreases in two well defined steps when the material undergoes its martensitic transformation. For the plain material a unique, profound dip is observed instead. This might be an effect of the high internal stresses level present in the composite. These internal stresses might have created a special variant configuration in the $R$ phase and have modified the dynamic mechanical properties accordingly. This interpretation needs further confirmation.

\section{References}

[1] C. A. Rogers, C. Liang, D.K. Barker, "Dynamic control concepts using shape memory alloy reinforced plates", U.S. Army Research Office Workshop on Smart Materials, Structures, and Math. Issues, Virginia Polytechnic Institute and State University Blacksburg, Virginia (1988) 39

[2] K. Escher, E. Hornbogen, "Aspects of two-way shape memory in NiTi-Silicon composite materials", J. de Physique, 1 (1991) C4-427

[3] H. G. Mooi, Master Thesis, "Active control of structural parameters of a composite strip using embedded shape memory alloy wires", University of Twente (1992)

[4] A. Venkatesh, J. Hilborn, J.-E. Bidaux, R. Gotthardt, "Active vibration control of flexible linkage mechanisms using shape memory alloy fiber-reinforced composites", Proc. First European Conf. on Smart Structures and Materials, Glasgow (1992) 185

[5] O. Mercier, K.N. Melton, R. Gotthardt, A. Kulik, "Lattice instability in the NiTi and NiTiCu alloys", Proc. of An Int. Conf. on Solid Solid Phase Transf., The Metall. Society of the AIME, Eds H. I. Aaronson et al, Pittsburgh (1981)

[6] S. K. Chaturvedi, G. Y. Tzeng, "Micromechanical modeling of material damping in discontinuous fiber three-phase polymer composites", Comp. Engineering, 1 (1991) 49-60 